\title{
Atributos físicos de solos sob diferentes usos com irrigação no semiárido de Pernambuco ${ }^{1}$
}

\author{
Rossini M. Corrêa ${ }^{2}$, Maria B. G. dos S. Freire 3 , Rinaldo L. C. Ferreira ${ }^{4}$, \\ José A. A. da Silva ${ }^{4}$, Luiz G. M. Pessoa ${ }^{5}$, Marcelo A. Miranda ${ }^{6} \&$ Diego V. M. de Melo 6
}

\begin{abstract}
RESUMO
Solos sob clima semiárido têm sido degradados pela salinização, reduzindo a capacidade produtiva. 0 bjetivou-se com este trabalho, avaliar atributos físicos dos solos de um perímetro irrigado no semiárido do Nordeste do Brasil e comparar diferentes usos utilizandose esses atributos. 0 trabalho foi desenvolvido no perímetro imigado Icó-M andantes, entre Petrolândia e Floresta, sertão de Pernambuco, no qual as populações foram estratificadas de acordo com os usos em áreas com culturas de ciclo curto (C), fruticultura (F), pastagem (P), áreas descartadas (D) e com vegetação nativa (V). Coletaram-se amostras de solo deformadas e indeformadas nas camadas de 0-10, 10-30 e 30-60 cm, para determinação dos atributos físicos. O sindicadores foram submetidos à análise multivariada, pela técnica de componentes principais e agrupamento pelo método Tocher. 0 uso agrícola promoveu alterações nos atributos físicos dos solos em relação à vegetação nativa. A qualidade do solo para os atributos físicos variou entre as camadas de 0-10 e 10-30 cm, exceto para o uso $\mathrm{V}$, com qualidade similar nessas camadas. Os usos $\mathrm{F}$ e $\mathrm{P}$ indicaram melhor qualidade física do solo em relação ao uso C, de 0-10 e 10-30 cm, e o uso D mostrou a pior qualidade do solo nas camadas avaliadas.
\end{abstract}

Palavras-chave: qualidade do solo, manejo do solo, vegetação nativa

\section{Physical attributes of soil under different uses with irrigation in semiarid Pernambuco}

\begin{abstract}
Soils in semiarid climate regions had been degraded by salinization, reducing their productive capacity. This work aimed to evaluate physical attributes of soil in an irrigated perimeter in the semiarid Northeast of Brazil and to compare different soil uses using these attributes. The study was carried out at I có-M andantes Irrigated Perimeter, between Petrolândia and Floresta, in semiarid region of Pernambuco, in which the populations were separated by their uses in annual crops (C), fruticulture (F), discarded lands $(D)$, pasture $(P)$, native vegetation $(V)$. Undisturbed and disturbed soil samples were collected, in layers of 0-10, 10-30 and 30-60 cm, for physical analysis. The indicators were submitted to multivariate analysis, by Principal Component Analysis, and clustering by the Tocher method. The agricultural use promoted alterations in the physical attributes of soil in relation to soil under native vegetation. The soil quality for the physical attributes varied between the layers of 0-10 and 10-30 cm, except in use $V$, sohich presented similar quality in these layers. $F$ and $P$ uses had presented better physical soil quality than $C$ use in the layers of $0-10$ and $10-30 \mathrm{~cm}$ and $D$ use presented the worst soil quality in the evaluated layers.
\end{abstract}

Key words: soil quality, soil management, native vegetation

\footnotetext{
1 Parte da tese de doutorado do primeiro autor no PPGCS/U FRPE

2 Doutor em Ciência do Solo/U FRPE. Rua Dom Manoel de Medeiros, s/n, Dois Irmãos. CEP 52171-900, Recife, PE. Fone (81) 3320-6220. E-mail: rossinimc@hotmail.com

${ }^{3}$ Departamento de Agronomia/UFRPE, Fone (81) 3320-6241. E-mail: betania@depa.ufrpe.br

${ }^{4}$ D epartamento de Ciência Florestal/UFRPE. Fone (81) 3320-6289; 3320-6288. E-mail: rinaldo@dcfl.ufrpe.br; jaaleixo@uol.com.br

${ }^{5}$ D outorando do PPGCS/UFRPE. Fone (81) 3320-6242. E-mail: pessoa.Igm@gmail.com

${ }^{6} \mathrm{G}$ raduando em Agronomia/UFRPE. Fone (81) 3320-6241. E-mail(s): marcelo_ufrpe@yahoo.com.br; diegoeari@yahoo.com.br
} 


\section{INTRODUÇãO}

A inclusão de áreas na atividade agrícola na região semiárida do Nordeste do Brasil deve assegurar, por meio da irrigação, a sustentabilidade ambiental da região sem a qual não haveria viabilidade econômica do empreendimento. A sustentabilidade de um perímetro irrigado está condicionada, dentre outros aspectos, à manutenção da produtividade dos solos que, dentro dos sistemas de produção, sofre modificações nos atributos biológicos, físicos e químicos, pela aplicação de fertilizantes e defensivos agrícolas, tráfego de máquinas e alteração do regime hídrico nas bacias hidrográficas.

Neste sentido, Carpenedo \& Mielniczuk (1990) observaram que o cultivo do solo altera alguns atributos físicos, com alterações mais pronunciadas nos sistemas convencionais de preparo que nos conservacionistas que se manifestam, em geral, na densidade do solo, volume e distribuição de tamanho dos poros e estabilidade dos agregados do solo, influenciando a infiltração da água, a erosão hídrica e o desenvolvimento das plantas.

O acompanhamento das alterações nos atributos dos solos em perímetros irrigados, fornecerá informações importantes sobre a qualidade do solo e sua capacidade produtiva, sendo esta modificada pelo uso, subsidiando a implantação de novos perímetros e o manejo do solo em perímetros em atividade.

Este monitoramento de atributos, trazendo informações para tomada de decisão relativa ao manejo do solo, pode ser observado no trabalho de Cunha et al. (2001), que constataram tendência de aumento na densidade do solo nos horizontes superficiais e subsuperficiais nos perfis cultivados durante um (soja), dois (soja-milho) e três anos (soja-milho-soja), em comparação com o solo sob vegetação nativa de cerrado; tal alteração decorreu, sem dúvida, da ação de implementos agrícolas utilizados (arados e grades), destruindo os agregados nos horizontes superficiais e aumentando a densidade de acomodação do solo, além de promover a compactação mecânica dos horizontes subsuperficiais (pé de grade/arado).

$\mathrm{Na}$ agricultura mecanizada, máquinas e implementos exercem pressões, podendo causar um rearranjo dos componentes sólidos do solo, desestruturando-o e o compactando, diminuindo, assim, sua porosidade. Deste modo e com o tempo, verifica-se maior densidade do solo sob manejo agrícola em relação ao encontrado em condições naturais (Anjos et al., 1994; Barber et al., 1996).

A incorporação de áreas sob vegetação nativa a sistemas agrícolas, normalmente provoca a diminuição do grau de floculação de argila, como observado por Rosa Júnior et al. (2006) em amostras de um Latossolo Vermelho Distroférrico coletadas sob três condições de uso: culturas anuais, pastagem e vegetação nativa. Segundo os autores, os valores de grau de floculação, influenciados pelo uso do solo, foram significativamente menores para os solos sob culturas anuais que para aqueles sob pastagem e vegetação nativa, que não apresentaram diferença significativa entre si.

Em geral, as práticas de manejo exercem maior impacto sobre as propriedades físicas de solos arenosos que de solos argilosos. Neste sentido, Silva \& Mielniczuk (1997) verificaram redução do diâmetro médio ponderado (DMP) dos agregados de $71 \%$ em um Argissolo Vermelho $\left(220 \mathrm{~g} \mathrm{~kg}^{-1} \mathrm{de}\right.$ argila) e de 47\% em Latossolo Roxo (680 $\mathrm{g} \mathrm{kg}^{-1}$ argila), quando passaram de uma condição de campo nativo para preparo convencional (aração e gradagem) com culturas anuais.

O conhecimento das propriedades físicas de solos irrigados sob diferentes usos em ambiente semiárido, fornecerá subsídios para a compreensão dos processos de degradação verificados nessas áreas, contribuindo para ajustes nas técnicas de manejo do solo, evitando a degradação deste recurso natural no Nordeste do Brasil. Propôs-se, com este trabalho, comparar os atributos de solos sob diferentes usos em um perímetro irrigado na região semiárida do Nordeste do Brasil, confrontando os respectivos usos adotados.

\section{MATERIAL E MÉTODOS}

O local de estudo foi o perímetro irrigado Icó-Mandantes, Bloco 3, situado nas margens do lago de Itaparica, municípios de Floresta e Petrolândia, PE, que faz parte do reassentamento realizado pela Companhia Hidro Elétrica do São Francisco (CHESF). Na área se encontram solos desenvolvidos de rochas sedimentares, basicamente arenitos e folhelhos calcíferos do Cretáceo. O clima da região do lago de Itaparica, segundo a classificação de Köppen, é caracterizado como BSw 'h', clima semiárido com curta estação chuvosa (média anual de $460 \mathrm{~mm}$ ) e a vegetação nativa da região é a caatinga hiperxerófila (THEMAG, 1986).

Utilizando-se o mapa de classificação de solos do perímetro, selecionaram-se áreas com solos de textura arenosa, em virtude de ocuparem cerca de $50 \%$ da área irrigada sendo, portanto, os mais representativos do perímetro. Todos os lotes foram visitados para levantamento dos usos e manejos aplicados registrando-se a área ocupada por cada uso e informações adicionais, como: tipo(s) de cultura(s), sistema de irrigação, situação de produção do lote e, quando necessário, a localização dos diferentes usos dentro do lote. Em suas ações, a CHESF realizou avaliação de alguns lotes agrícolas quanto a viabilidade de produção considerando aspectos, como profundidade do solo e altura do lençol freático. Em alguns casos, os lotes foram considerados impróprios para o cultivo e descartados para uso agrícola. Estas áreas, denominadas de agora em diante de áreas descartadas, foram identificadas de acordo com os registros da CHESF onde, para cada lote com área descartada, havia uma ficha de tradagem com a localização no lote desta área, o que permitiu no momento da visita a sua localização.

Foi possível, então, classificar os usos em:

1) Ciclo curto (C): Áreas cultivadas com culturas anuais, ressaltando-se, como mais representativas para o uso, abóbora, melancia, coentro, milho e feijão cujo manejo se compunha, de modo geral, de uma aração e duas gradagens no preparo do solo, no início de cada cultivo, duas a três vezes ao ano, caracterizando este sistema como de grande movimentação de solo;

2) Fruticultura (F): Áreas cultivadas, predominantemente, com bananeira, coqueiro, goiabeira e mangueira, movimentação do solo por aração e gradagem apenas na implantação das culturas, sem uso de máquinas nas operações de colheita e tratos fitossanitários; 
3) Pastagem (P): Áreas utilizadas como pastagem nativa continuamente, em alguns casos e, em outros, entre períodos de cultivo de culturas de ciclo curto mais espaçados, apresentando movimentação do solo intermediária entre os usos $\mathrm{C}$ e $\mathrm{F}$, em que, de modo geral pratica-se, para a manutenção da pastagem, uma superirrigação, com manejo de irrigação reduzido;

4) Área descartada (D): Áreas identificadas pela CHESF, observando-se a presença dos usos descritos anteriormente e de áreas abandonadas com regeneração de vegetação nativa. A particularidade dessas áreas é que, após alguns anos de cultivo, foram classificadas como áreas impróprias ao cultivo, o que constituiu o interesse de investigação uma vez que problemas de degradação poderiam ser aqui identificados em grau avançado possibilitando uma análise comparativa com os outros usos;

5) Vegetação nativa (V): Áreas originalmente de caatinga, sem intervenção humana nem histórico de cultivo agrícola.

Ressalta-se que os usos relacionados a sistemas agrícolas, ou seja, C, F, P e D, eram conduzidos com a prática da irrigação. Contudo, no uso $\mathrm{D}$, onde que se observava a área sem cultivo e com sinais de regeneração da vegetação, não estava atualmente sendo irrigado. Contrariamente, as áreas de vegetação nativa não haviam sido irrigadas.

Após a definição da área total e localização das áreas de cada uso no mapa, foi possível elaborar o plano de amostragem. Considerando a hipótese de não homogeneidade dos atributos dos solos submetidos a diferentes usos e manejos, adotou-se amostragem aleatória estratificada, como descrito por Meunier et al. (2001). A unidade de amostra foi definida com área de 0,5 ha, submúltiplo da área dos lotes (1,5, 3,0, 4,5 e 6,0 ha). Cada unidade localizada no mapa recebeu um código identificador para sorteio; as unidades selecionadas no sorteio representavam um ponto marcado no mapa, em que se obtinha uma coordenada geográfica a ser localizada em campo.

Estabeleceram-se, por uso, 15 repetições, uma em cada unidade amostral de 0,5 ha e constituída de uma amostra simples coletada nas camadas de 0-10, 10-30 e 30-60 cm de profundidade totalizando, nos cinco usos, 225 amostras; no ponto de coleta da amostra também se registrou a profundidade do solo por tradagem até a camada impermeável, ou a 2,2 metros de profundidade, considerada propriedade física do solo. Simultaneamente se tomou uma amostra indeformada na camada de $0-10 \mathrm{~cm}$ e outra na de 10-30 cm com cilindro volumétrico para determinação da densidade do solo. As amostras de solo foram secadas ao ar, destorroadas e passadas em peneira de $2 \mathrm{~mm}$ de malha visando ao procedimento das análises físicas (EMBRAPA, 1997).

Determinaram-se, na caracterização física, a composição granulométrica e a argila dispersa em água (ADA) pelo método do densímetro, a densidade do solo (Ds) pelo método do cilindro volumétrico (amostra indeformada), a densidade das partículas com o balão volumétrico e a condutividade hidráulica em meio saturado com o permeâmetro de coluna vertical e carga constante (EMBRAPA, 1997). De posse dos dados de densidade do solo e das partículas, calculou-se a porosi- dade total (PT) e, com os de argila total e argila dispersa em água, o grau de floculação (GF).

Realizou-se a estatística descritiva dos resultados para a obtenção das médias de cada atributo por uso do solo e se utilizou a análise de componentes principais de acordo com Souza (2001) para a avaliação das características dos solos nos conjuntos de atributos físicos acima citados. Como critério se adotou o menor número de componentes principais contanto que esses componentes envolvessem um mínimo de $80 \%$ da variação total (Cruz et al., 2004). A análise de agrupamento pelo método Tocher, conforme Rao (1952), foi realizada a partir dos escores das componentes principais retidas para interpretação, de acordo com o critério apresentado acima aplicando-se, como medida de dissimilaridade, a distância Euclidiana Média.

\section{RESULTADOS E DISCUSSÃO}

No uso D se observou o maior valor médio de densidade das partículas nas três camadas avaliadas, seguido do uso $\mathrm{C}$; os demais usos mostraram valores menores e semelhantes entre si (Tabela 1).

Os valores médios de densidade do solo foram semelhantes para o uso V nas camadas avaliadas (Tabela 1). Verificaram-se, para os outros usos, maiores valores médios da densidade do solo na camada de 10-30 cm em comparação com a camada de 0-10 cm (Tabela 1); possivelmente, práticas corriqueiras na região, como aração e gradagem, diminuíram a densidade do solo na camada superficial dos usos D, C, F e P, resultado semelhante ao obtido por Figueiredo et al. (2009), que avaliaram os atributos físico-hídricos do solo sob diferentes sistemas de manejo em comparação com o cerrado nativo. Esses autores verificaram menores valores de densidade do solo na camada superficial $(0-10 \mathrm{~cm})$ nos sistemas S1 (soja/feijão/arroz/milheto/feijão) e S2 (soja/milheto/milho) em comparação com a camada subsuperficial $(10-20 \mathrm{~cm})$ o que não se observou no sistema S3 (milho + pastagem - integração-lavoura-pecuária).

$\mathrm{Na}$ camada de 10-30 cm se constataram, nos usos $\mathrm{C}$ e $\mathrm{D}$, valores discretamente superiores de densidade do solo que o observado para o uso V (Tabela 1), corroborando com Figueiredo et al. (2009), que verificaram aumento significativo da densidade do solo em sistemas manejados, em comparação com a vegetação nativa. Visto que os usos C e D foram submetidos a uma movimentação maior do solo (aração e gradagem) em função do manejo produtivo adotado na região, é provável que tenha ocorrido uma compactação do solo em função do tráfego de máquinas ou adensamento desta camada, pela migração de partículas coloidais no perfil do solo.

Silva et al. (2005) observaram a influência do manejo do solo nos atributos físicos e avaliaram o efeito de longo prazo (17 anos) dos sistemas de preparo convencional, preparo reduzido e semeadura direta sobre os atributos físicos de um Argissolo Vermelho, com textura média no Rio Grande do Sul; adicionalmente se incorporou, ao estudo, uma área de campo 
Tabela 1. Média e desvio padrão (s) de atributos físicos dos solos correspondentes aos usos: ciclo curto (C), área descartada (D), fruticultura $(F)$, pastagem $(P)$ e vegetação nativa $(V)$

\begin{tabular}{|c|c|c|c|c|c|c|c|c|c|c|c|}
\hline \multirow{3}{*}{ Atributo } & \multirow{3}{*}{$\begin{array}{c}\text { Camada } \\
\text { (cm) }\end{array}$} & \multicolumn{10}{|c|}{ Uso } \\
\hline & & \multicolumn{2}{|c|}{ C } & \multicolumn{2}{|c|}{ D } & \multicolumn{2}{|c|}{$\mathbf{F}$} & \multicolumn{2}{|c|}{$\mathbf{P}$} & \multicolumn{2}{|c|}{$\mathbf{v}$} \\
\hline & & Média & s & Média & $S$ & Média & $\mathbf{s}$ & Média & s & Média & s \\
\hline \multirow{3}{*}{$\mathrm{Dp}\left(\mathrm{kg} \mathrm{dm}^{-3}\right)$} & $0-10$ & 2,56 & 0,10 & 2,60 & 0,08 & 2,48 & 0,08 & 2,50 & 0,08 & 2,50 & 0,08 \\
\hline & $10-30$ & 2,57 & 0,10 & 2,62 & 0,09 & 2,48 & 0,09 & 2,51 & 0,09 & 2,49 & 0,07 \\
\hline & $30-60$ & 2,56 & 0,13 & 2,59 & 0,10 & 2,52 & 0,11 & 2,52 & 0,10 & 2,49 & 0,13 \\
\hline \multirow{2}{*}{ Ds $\left(\mathrm{kg} \mathrm{dm}^{-3}\right)$} & $0-10$ & 1,65 & 0,07 & 1,69 & 0,07 & 1,62 & 0,06 & 1,60 & 0,14 & 1,69 & 0,08 \\
\hline & $10-30$ & 1,76 & 0,16 & 1,80 & 0,10 & 1,72 & 0,10 & 1,70 & 0,14 & 1,69 & 0,15 \\
\hline \multirow{3}{*}{$P\left(m^{3} m^{-3}\right)$} & $0-10$ & 0,36 & 0,04 & 0,35 & 0,03 & 0,35 & 0,04 & 0,36 & 0,06 & 0,33 & 0,05 \\
\hline & $10-30$ & 0,32 & 0,07 & 0,31 & 0,05 & 0,31 & 0,05 & 0,32 & 0,06 & 0,32 & 0,07 \\
\hline & $0-10$ & 860,1 & 45,7 & 848,0 & 32,1 & 881,0 & 69,7 & 891,6 & 27,7 & 876,9 & 34,0 \\
\hline \multirow[t]{3}{*}{ Areia $\left(\mathrm{g} \mathrm{kg}^{-1}\right)$} & $10-30$ & 844,5 & 32,6 & 820,5 & 55,7 & 877,9 & 24,0 & 869,3 & 29,1 & 873,2 & 28,8 \\
\hline & $30-60$ & 825,7 & 50,5 & 813,1 & 62,4 & 861,7 & 21,5 & 840,3 & 48,6 & 866,5 & 19,1 \\
\hline & $0-10$ & 40,1 & 22,2 & 37,6 & 13,7 & 42,2 & 67,1 & 24,6 & 17,2 & 25,2 & 16,8 \\
\hline \multirow[t]{3}{*}{ Silte $\left(\mathrm{g} \mathrm{kg}^{-1}\right)$} & $10-30$ & 33,1 & 17,1 & 33,1 & 10,5 & 20,2 & 7,5 & 21,4 & 9,7 & 18,9 & 11,0 \\
\hline & $30-60$ & 36,0 & 19,0 & 33,2 & 11,8 & 25,1 & 10,1 & 26,8 & 14,8 & 21,9 & 9,6 \\
\hline & $0-10$ & 99,9 & 29,6 & 114,4 & 22,5 & 76,8 & 11,4 & 83,8 & 19,7 & 98,0 & 20,0 \\
\hline \multirow[t]{3}{*}{ Argila $\left(\mathrm{g} \mathrm{kg}^{-1}\right)$} & $10-30$ & 122,4 & 24,1 & 146,4 & 56,7 & 101,9 & 22,8 & 109,3 & 25,5 & 107,9 & 21,0 \\
\hline & $30-60$ & 138,2 & 36,4 & 153,7 & 55,9 & 113,3 & 19,4 & 132,9 & 39,1 & 111,6 & 10,7 \\
\hline & $0-10$ & 73,2 & 29,1 & 79,4 & 28,1 & 49,7 & 16,0 & 48,1 & 25,4 & 63,3 & 11,7 \\
\hline \multirow[t]{3}{*}{$\mathrm{ADA}\left(\mathrm{g} \mathrm{kg}^{-1}\right)$} & $10-30$ & 90,3 & 21,7 & 118,4 & 56,9 & 76,1 & 23,1 & 76,3 & 34,0 & 68,2 & 13,5 \\
\hline & $30-60$ & 87,0 & 42,8 & 110,3 & 66,2 & 77,1 & 29,5 & 86,8 & 54,7 & 72,6 & 16,7 \\
\hline & $0-10$ & 29,65 & 11,1 & 31,46 & 16,42 & 36,56 & 18,53 & 45,80 & 25,26 & 34,95 & 7,44 \\
\hline \multirow[t]{3}{*}{ GF (\%) } & $10-30$ & 26,58 & 6,3 & 20,46 & 9,59 & 26,24 & 8,19 & 32,48 & 23,71 & 36,61 & 5,31 \\
\hline & $30-60$ & 37,40 & 20,5 & 29,91 & 23,36 & 32,48 & 20,75 & 36,50 & 28,12 & 35,23 & 11,94 \\
\hline & $0-10$ & 25,89 & 15,8 & 21,99 & 9,90 & 38,86 & 16,73 & 30,30 & 12,19 & 17,75 & 9,41 \\
\hline \multirow[t]{2}{*}{ Ko $\left(\mathrm{cm} \mathrm{h}^{-1}\right)$} & $10-30$ & 18,68 & 7,9 & 16,98 & 8,97 & 30,81 & 14,24 & 26,18 & 12,49 & 20,24 & 17,61 \\
\hline & $30-60$ & 19,56 & 13,6 & 16,59 & 11,11 & 28,40 & 12,18 & 17,86 & 12,11 & 13,41 & 5,94 \\
\hline Prof. (m) & - & 1,81 & 0,52 & 1,11 & 0,66 & 2,11 & 0,25 & 1,96 & 0,51 & 1,93 & 0,49 \\
\hline
\end{tabular}

Dp - densidade das partículas; Ds - densidade do solo; P - porosidade total; ADA - argila dispersa em água; GF - grau de floculação; Ko - condutividade hidráulica em meio saturado; Prof - profundidade do solo

nativo, como referência à condição natural do solo. Esses autores notaram que a porosidade total variou mais com a profundidade que com os sistemas de preparo do solo; este atributo apresentou maiores valores em superfície que em subsuperfície, resultados semelhantes aos observados neste estudo para os usos C, D, F e P (Tabela 1) resultado, provavelmente, das práticas de aração e gradagem do solo e da maior concentração de C-orgânico (Corrêa et al., 2009) na camada superficial resultante da deposição de matéria orgânica da vegetação. No uso $\mathrm{V}$ não se observou variação expressiva da porosidade total com a profundidade (Tabela 1).

Araújo et al. (2004) estudaram algumas propriedades indicadoras da qualidade física de um Latossolo Vermelho distrófico da região Noroeste do Paraná, cultivado e sob mata nativa, e verificaram valores significativamente maiores de densidade do solo e menores de porosidade total na área cultivada. Observou-se, no presente estudo, resultado contrário ao desses autores, na camada de 0-10 $\mathrm{cm}$. Nesta camada e em comparação com os usos relacionados a sistemas de produção, $\mathrm{V}$ teve menor valor de porosidade total e maior valor de densidade do solo, exceto em relação ao uso D, observando-se o mesmo valor médio de densidade do solo (Tabela 1).

A avaliação da camada de $10-30 \mathrm{~cm}$ apresentou resultados semelhantes (Tabela 1) aos observados por Araújo et al.
(2004), cuja vegetação nativa mostrou menor densidade do solo em relação aos usos $\mathrm{C}$ e $\mathrm{D}$, e contrários, quando se observou que a densidade do solo em $\mathrm{V}$ foi semelhante aos usos F e P. Ressalta-se que na camada de $0-10 \mathrm{~cm}$ os efeitos das práticas de aração e gradagem são, normalmente, positivos, com diminuição da densidade do solo constatando-se que, com o passar do tempo, ocorre a acomodação das partículas do solo podendo a densidade final ser maior que a inicial em função do rompimento dos agregados do solo.

A variação dos atributos do solo em função do uso foi constatada por Su et al. (2004), que analisaram os usos: cultivo de ciclo curto por três anos (CC), pastejo contínuo (PC) e pousio por cinco anos (P5) e observaram que a densidade do solo no $\mathrm{P} 5$ foi significativamente inferior em relação ao $\mathrm{CC}$ e à área de PC, na camada de $0-2,5 \mathrm{~cm}$ e, na camada de $0-7,5 \mathrm{~cm}$ foi inferior apenas ao CC. Este resultado foi semelhante ao obtido neste trabalho, em que o uso $\mathrm{C}$ indicou valor de densidade do solo superior àquele observado para o uso P (Tabela 1); entretanto, as alterações na densidade do solo foram verificadas em camadas mais profundas que 7,5 cm observando-se, neste trabalho, discretas alterações na densidade do solo na camada de 10-30 $\mathrm{cm}$ para os usos C e D em relação ao uso V (Tabela 1).

Pela composição granulométrica média das amostras de solo estudadas, observou-se predomínio da fração areia em 
relação às demais, confirmando a classificação dos solos como de textura arenosa (Tabela 1); contudo, os teores de areia são superiores na camada superficial, contrariamente aos de argila, que crescem em profundidade em consequência, possivelmente, da migração de colóides ao longo do perfil do solo.

Observando-se os resultados da ADA em profundidade, verificaram-se incrementos nessa variável, sobretudo no uso $\mathrm{D}$, passando de $79,4 \mathrm{~g} \mathrm{~kg}^{-1}$ na camada de $0-10 \mathrm{~cm}$ para 110,3 $\mathrm{g} \mathrm{kg}^{-1}$ da argila total na camada de $30-60 \mathrm{~cm}$ (Tabela 1 ), o que pode ser indicativo de um processo de migração de colóides no perfil do solo, mais acentuado nos usos relacionados a sistemas produtivos com aumento na dispersão em profundidade, passível de acarretar a formação de camadas de impedimento pela migração de partículas finas e sua concentração em algum ponto do perfil do solo; inclusive, no uso $\mathrm{D}$, de baixa profundidade do solo, este efeito pode ser potencializado em função da proximidade da camada de impedimento dificultando, ainda mais, o movimento de água nesta camada. Prado \& Centurion (2001) e Maia et al. (2006) notaram incremento da ADA com a profundidade concordando com os resultados obtidos neste estudo (Tabela 1).

Silva et al. (2006) estudaram os efeitos de diferentes sistemas de manejo com cana-de-açúcar nas propriedades físicas e químicas de um Argissolo Amarelo Coeso, selecionando quatro sistemas de uso e manejo, constituídos de uma área não irrigada, uma área irrigada, uma com aplicação de vinhaça e uma sob floresta nativa, como condição original. Os sistemas de manejo com cana-de-açúcar influenciaram as propriedades físicas do solo, ocorrendo aumento da argila dispersa em água e redução da estabilidade dos agregados em água dos solos cultivados, em relação ao solo da mata. Resultados semelhantes foram observados neste trabalho, em que os usos C e D apresentaram valores discretamente superiores de ADA nas três camadas avaliadas em relação ao uso $\mathrm{V}$ (Tabela 1) devido, possivelmente, ao efeito do revolvimento do solo propiciando a destruição da estrutura do solo e a dispersão dos colóides. O mesmo foi observado para os usos $\mathrm{F}$ e $\mathrm{P}$, que apresentaram valores superiores de ADA em comparação com o uso V, nas camadas de 10-30 e 30-60 cm mas se encontrou um resultado diferente do observado por Silva et al. (2006) na camada de 0-10 cm quando então os usos F e $\mathrm{P}$ apresentaram valores de ADA menores que os observados em V (Tabela 1).

Verificaram-se no solo submetido ao uso F, os maiores valores médios para a condutividade hidráulica, em todas as camadas avaliadas, seguido do uso $\mathrm{P}$, nas camadas de 0-10 e $10-30 \mathrm{~cm}$ e do uso C, na camada de 30-60 cm (Tabela 1). Observou-se, nas três camadas, o seguinte padrão de distribuição das médias entre os usos C e D: o uso C apresentou maiores valores em todas as camadas e entre os usos $\mathrm{P}$ e $\mathrm{V}$, o uso $\mathrm{P}$ mostrou maiores valores de condutividade hidráulica em todas as camadas (Tabela 1). O uso $\mathrm{V}$ teve os menores valores de condutividade hidráulica, exceto na camada de 10$30 \mathrm{~cm}$, quando comparado com os usos C e D. Este resultado é contrário ao obtido por Borges et al. (2009), avaliando atributos físico-hídricos de Latossolo Vermelho sob pastejo e cerrado, que constataram que o solo sob cerrado natural e cerrado antropizado (pastejo no verão) apresentou maiores valores de condutividade hidráulica saturada determinada em campo com permeâmetro de Guelph, nas camadas de 10-15 e de 40-55 em comparação com o solo manejado nos sistemas de pastagens com alto, médio e baixo grau de cobertura do solo.

Observaram-se, ao se avaliar a profundidade da camada de impedimento dos solos, valores médios elevados nos usos F, $\mathrm{C}, \mathrm{P}$ e V , enquanto no uso $\mathrm{D}$ a profundidade média foi de 1,11 $\mathrm{m}$ (Tabela 1). A baixa profundidade do solo do D dificulta a drenagem do solo, a lixiviação dos sais e estabelece a aproximação do lençol freático com a superfície, potencializando a ascensão capilar de sais que, acumulados na camada superficial ao longo do tempo, podem atingir teores limitantes ao pleno desenvolvimento das culturas, o que não foi observado em virtude, possivelmente, do curto período de operação do perímetro. Adicionalmente, a proximidade do lençol freático da superfície prejudica o crescimento de plantas pela deficiência de oxigênio e redução da camada explorada de solo.

Observando-se os valores médios das variáveis dos atributos físicos (Tabela 1), verificou-se que não há valor que possa, ainda, identificar algum uso e seu solo correspondente como de má qualidade, pois se encontraram valores comumente observados para solos em geral; contudo, há indicativos de alterações nos atributos avaliados em profundidade nos usos agrícolas o que não é observado em V, passível de comprometer, futuramente, a qualidade desses solos. Deste modo, os comentários relativos aos atributos físicos classificam os usos entre si, considerando-os de boa qualidade do solo, destacando-se apenas o uso D que, pelo seu valor médio de profundidade, foi considerado de má qualidade do solo; referidas áreas estavam constantemente com o solo saturado por água em função da deficiência de drenagem.

Os usos F e $\mathrm{P}$ tiveram a melhor qualidade física na camada de $0-10 \mathrm{~cm}$, entre os usos produtivos; possivelmente, a menor movimentação do solo no seu manejo permitiu uma agregação maior das partículas do solo, o que foi verificado pelo maior valor de grau de floculação observado por esses usos, entre outras variáveis com melhor qualidade; constatou-se, no uso $\mathrm{C}$, qualidade inferior aos usos $\mathrm{F}$ e $\mathrm{P}$, com maior densidade do solo e menor grau de floculação de argila devido, sem dúvida, ao manejo com intensa movimentação do solo (Tabela 1). O uso V mostrou, como pontos negativos, a maior densidade do solo talvez por nunca ter sido arado ou gradeado, e maior ADA devido, supõe-se, aos baixos teores de cátions floculantes, uma vez que este uso não recebeu corretivo de acidez, como os usos agrícolas. Na camada de $0-10 \mathrm{~cm}$, o uso D reuniu atributos não desejáveis, como menor profundidade e maior densidade do solo e ADA que, entre outros, colaboraram para que este apresentasse a pior qualidade do solo (Tabela 1). Ressalta-se o potencial do uso V para atividade agrícola devido à boa qualidade do solo sob este uso.

Borges et al. (2009), em estudo sobre a qualidade físicohídrica de solo em área sobre pastejo em comparação a um cerrado natural, concluíram que a camada superficial do solo foi a mais prejudicada pelo pastejo, com perda da qualidade físico-hídrica e redução na capacidade de infiltração de água, o que não foi verificado em camadas mais profundas do solo. 
Na camada de 10-30 cm do uso $\mathrm{D}$, adicionalmente à baixa profundidade do solo, observaram-se valores de outras variáveis, a exemplo da densidade do solo, ADA e grau de floculação (Tabela 1), que contribuíram negativamente para a qualidade do solo deste uso. $\mathrm{O}$ uso $\mathrm{C}$, provavelmente devido à mecanização do solo, teve variáveis, como condutividade hidráulica e densidade do solo, que contribuíram, dentre outras, para uma qualidade do solo inferior ao uso $\mathrm{P}$, enquanto o uso $\mathrm{V}$ assumiu a posição de melhor qualidade do solo nesta camada, em virtude de não sofrer o efeito da mecanização do solo que atinge, sobretudo, a camada subsuperficial, apresentando menores valores de ADA e densidade do solo e, ainda, maiores de grau de floculação, dentre outras variáveis (Tabela 1).

Na camada de 30-60 cm do uso D, verificou-se o maior valor de ADA, além da baixa profundidade do solo o que, entre outras variáveis, colaborou para a menor qualidade do solo. Menos afetada pelo manejo, a avaliação da qualidade do solo nesta camada permitiu que variáveis intrínsecas pudessem se sobrepor àquelas relacionadas ao manejo do solo fazendo com que o uso $\mathrm{C}$ apresentasse a melhor qualidade do solo; observou-se, ainda, que o grau de floculação verificado no uso $\mathrm{C}$ apresentou bom resultado em relação aos demais usos.

Reunindo-se as informações sobre a avaliação da qualidade do solo nas três camadas analisadas para os atributos físicos concluiu-se, em uma avaliação geral, que o uso D apresentou a pior qualidade em todas as camadas analisadas, em função não só da profundidade do solo mas também de atributos relacionados ao manejo (Tabela 1).

Os usos P e F indicaram, nas camadas de 0-10 e de 10-30 $\mathrm{cm}$, melhor qualidade do solo em relação ao uso $\mathrm{C}$, em virtude do manejo menos intenso do solo, típico desses usos. Na camada de $0-10 \mathrm{~cm}$, o uso $\mathrm{V}$ assumiu posição inferior aos usos C, F e P, provavelmente pelos benefícios da aração e gradagem, expressos na camada superficial dos solos cultivados; no entanto, os benefícios da mecanização do solo obtidos na camada de 0-10 cm não foram estendidos às camadas inferiores que, em geral, são afetadas apenas pelo efeito da compactação do solo.

Deste modo, na camada de $10-30 \mathrm{~cm}$ as posições se inverteram e o uso $\mathrm{V}$ apresentou melhor qualidade que os usos $\mathrm{C}$, F e P; este resultado foi obtido, sem dúvida, pela não movimentação do solo por máquinas agrícolas causadoras da compactação e pela cobertura do solo oferecida por uma vegetação nativa atuando na sua proteção. Nas camadas analisadas de 0-10 e 10-30 cm, mais influenciadas pelo manejo, o uso C apresentou qualidade física do solo inferior à dos usos $\mathrm{P}$ e $\mathrm{F}$ indicando que no uso $\mathrm{C}$ o impacto negativo do manejo do solo deve ser reduzido para que este melhore a qualidade.

A análise de componente principal (ACP) indicou que duas primeiras componentes principais para os atributos físicos avaliados na camada de $0-10 \mathrm{~cm}$ explicaram $85,46 \%$ da variação total. A análise de agrupamento pelo método Tocher utilizando-se essas componentes principais, formou dois grupos, em que no primeiro se encontraram os usos C, D, F e P e, isolado em um grupo, ficou o uso V (Figura 1A)

Os usos agrícolas estudados se apresentaram similares para os atributos físicos avaliados na camada de $0-10 \mathrm{~cm}$ conside-
A.

Camada de $0-10 \mathrm{~cm}$
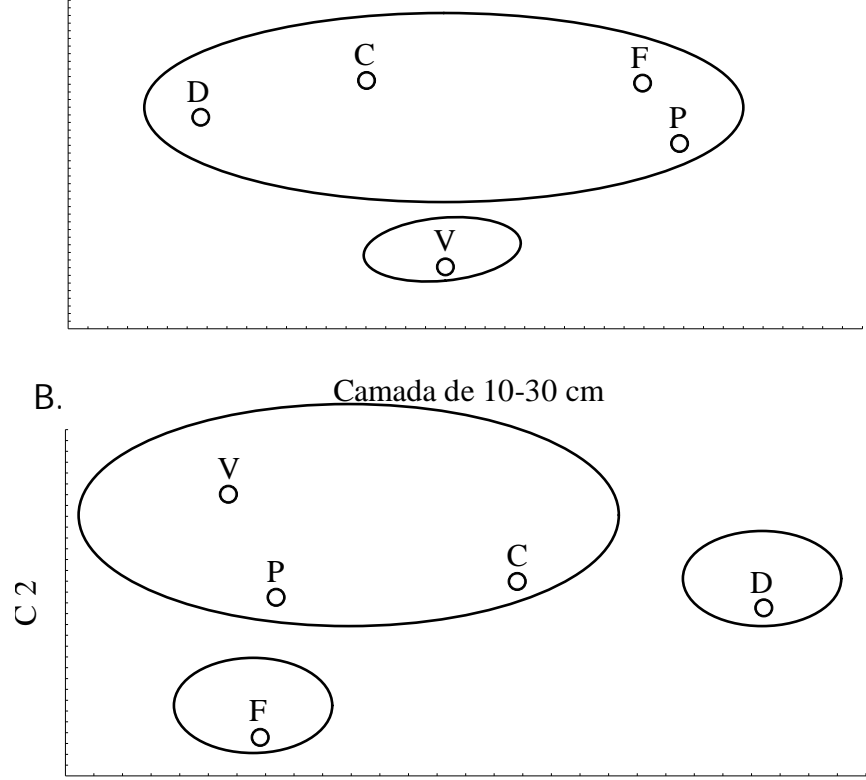

C.

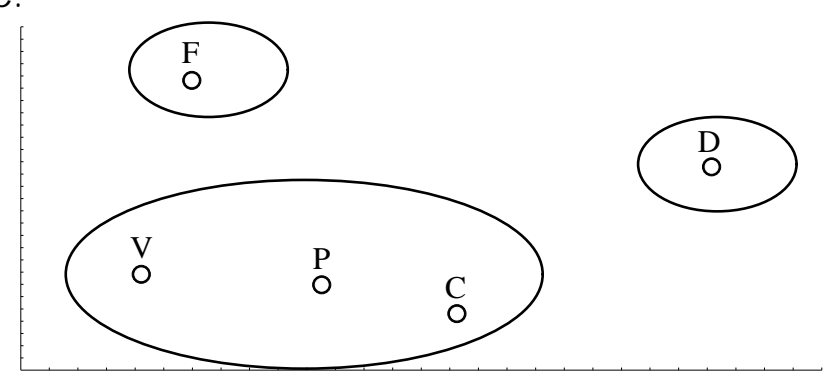

C 1

Figura 1. Dispersão dos atributos físicos por camada de solo em relação às componentes principais ( $\mathrm{C} 1$ e $\mathrm{C2}$ ) agrupadas pelo método Tocher (círculos e elipses) para os usos ciclo curto (C), área descartada (D), fruticultura (F), pastagem (P) e vegetação nativa (V). A - Camada 0-10 cm, B - Camada 10-30 cm, C Camada $30-60 \mathrm{~cm}$

rando-se a análise de agrupamento (Figura 1A). O uso V isolado em um grupo (Figura 1A) evidenciou que a prática agrícola causou alteração nos atributos físicos do solo quando estes, sob vegetação nativa, foram incorporados aos sistemas produtivos. Resultados semelhantes foram observados por outros autores que verificaram modificações expressivas das características físicas de solo após a incorporação em sistemas agrícolas.

Segundo Rosa Júnior et al. (2006), os valores de grau de floculação foram influenciados pelo uso do solo, sendo significativamente inferiores para as condições sob culturas anuais que para os solos sob pastagens e vegetação nativa, que não apresentaram diferença significativa entre si. Souza et al. (2005) avaliaram atributos físicos em um Neossolo Quartzarênico, sob diferentes usos: milho, soja, pastagem, integração lavoura-pecuária e cerrado antropizado. Os referidos autores observaram que neste solo ocorreu uma redução no volume total de poros e na macroporosidade, além de aumento na densidade do solo, em todas as áreas estudadas, quando comparadas com o cerrado nativo, com exceção do cerra- 
do antropizado. É provável que a mecanização do solo e o pisoteio do gado tenham contribuído para a diminuição da qualidade do solo.

$\mathrm{Na}$ camada de 10-30 cm, a análise de agrupamento pelo método de otimização de Tocher, aplicada aos escores das componentes principais 1 e 2, contendo, juntas, 96,34\% da variação total, identificou três grupos. Em um grupo estão contidos os usos C, P e V, os usos F e D se constituíram em conjuntos unitários (Figura 1B).

Para as variáveis físicas analisadas na camada de $10-30 \mathrm{~cm}$, ficou patente que as influências do manejo de solo não alteraram, de maneira expressiva, esses atributos nos usos $\mathrm{C}$ e $\mathrm{P}$, uma vez que estes formaram um grupo, juntamente com o uso de vegetação nativa (Figura $1 \mathrm{~B}$ ), considerando o ponto de partida de onde o solo foi alterado em função dos usos agrícolas. Resultados semelhantes foram observados por Barreto et al. (2006) na avaliação da substituição da vegetação nativa de Mata Atlântica pelos sistemas agrícolas de produção de cacau e pastagem, em que as características físicas densidade do solo, porosidade total, capacidade de campo e ponto de murcha permanente não apresentaram diferença significativa entre os usos agrícolas em comparação com a vegetação nativa. Analisando-se a disposição dos usos nos grupos, temse que nesta camada as influências nos atributos físicos ficaram restritas aos usos $\mathrm{F}$ e D (Figura 1B).

Leonardo (2003) avaliou a qualidade do solo na bacia do rio Passo Cue e verificou os atributos biológicos, físicos e químicos, em amostras coletadas até a profundidade de $40 \mathrm{~cm}$, em área sob vegetação nativa e duas áreas agrícolas com diferentes manejos (cultivo mínimo e plantio direto). Este autor notou que o solo sob vegetação nativa apresentou melhor qualidade diferenciando-se quanto aos atributos físicos analisados em relação aos sistemas agrícolas avaliados, resultados diferentes dos obtidos neste trabalho, no qual se verificou similaridade entre $\mathrm{V}$ e os usos $\mathrm{C}$ e $\mathrm{P}$ (Figura $1 \mathrm{~B}$ e $1 \mathrm{C}$ ).

Os atributos físicos da camada de $30-60 \mathrm{~cm}$ submetidos à análise de componentes principais, apresentaram duas componentes principais, retidas conforme o critério adotado. A análise de agrupamento pelo método Tocher a partir das duas primeiras componentes principais que, juntas, reuniram $84,87 \%$ da variação total, dividiu os usos em três grupos em que um reuniu, como usos similares, $\mathrm{C}, \mathrm{P}$ e V e dois conjuntos unitários formados pelos usos D e F (Figura 1C).

A análise de agrupamento para os atributos físicos na camada de 30-60 cm teve resultado igual ao apresentado para a camada de 10-30 cm (Figura 1B e C). Infere-se que as alterações nos atributos físicos provocadas pelo manejo do solo nos usos F e D atingiram esta camada diferenciando-as do V, em estado original, entre os quais a intensidade das alterações foi diferente, o que os tornou não similares, de acordo com a análise de agrupamento. Observou-se que, possivelmente, em $\mathrm{C}$ e $\mathrm{P}$ o manejo do solo não provocou alterações nos seus atributos físicos uma vez que estes usos ficaram no mesmo grupo que V. Por fim, para $\mathrm{C}$ e $\mathrm{P}$ as alterações provocadas pelo manejo se restringem à camada de $0-10 \mathrm{~cm}$ não ocorrendo modificações mais expressivas nas camadas inferiores avaliadas. Em D e F essas alterações se estendem da primeira à última camada avaliada (Figura $1 \mathrm{~A}, \mathrm{~B}$ e C).
Avaliou-se a distribuição espacial nas camadas de 0-10 e de 10-30 cm, para verificação de gradiente vertical da qualidade do solo. A análise de agrupamento pelo método Tocher a partir das duas primeiras componentes principais, que juntas reuniram $87,13 \%$ da variação total, dividiu os usos em quatro grupos (Figura 2). Observou-se, em V, qualidade do solo similar nas duas camadas representadas por V1, camada de 0-10 cm, e V2, camada de 10-30 cm, pertencendo ao mesmo grupo (Figura 2).

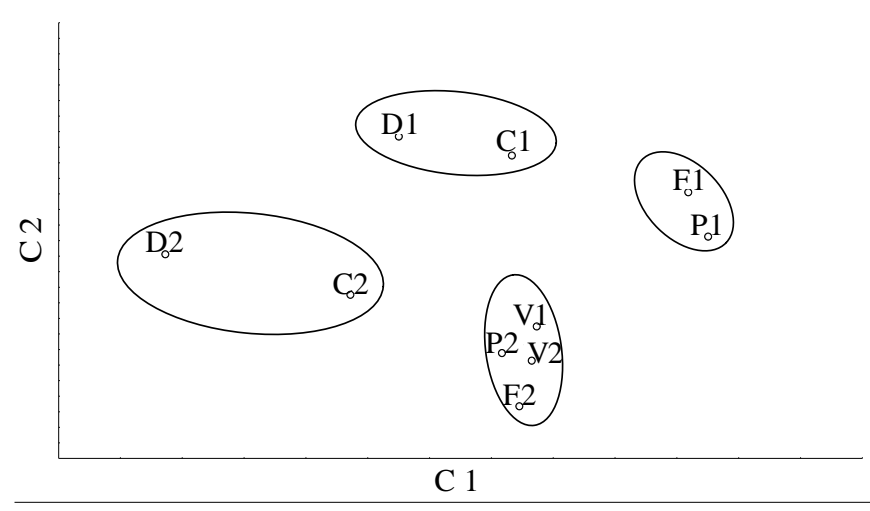

Figura 2. Dispersão dos atributos físicos nas camadas de solo de 0-10 e 10$30 \mathrm{~cm}$ em relação às componentes principais ( $\mathrm{C} 1 \mathrm{e} C 2$ ) agrupadas pelo método Tocher (círculos e elipses) para os usos ciclo curto (C), área descartada (D), fruticultura (F), pastagem (P) e vegetação nativa (V). Os símbolos dos usos seguidos dos números 1 e 2 representam, respectivamente, as camadas de $0-10 \mathrm{~cm}$ e $10-30 \mathrm{~cm}$

Os usos produtivos avaliados apresentaram, por outro lado, variação dos atributos físicos, observando-se, em grupos distintos, as informações sobre esses usos relativas às diferentes camadas avaliadas (Figura 2). Este resultado foi semelhante ao obtido por Fidalski et al. (2007) que, estudando a espacialização da qualidade física de um Latossolo cultivado com citros em três posições (projeção da copa, entrelinha e rodado da entrelinha), observaram diferença entre a qualidade física da camada superficial (0-20 $\mathrm{cm})$ e a subsuperficial $(20-40 \mathrm{~cm})$. Os autores concluíram que o impacto do uso e o manejo desse solo com o tráfego de máquinas e implementos não alteraram a qualidade física do solo em subsuperfície com o que, no presente estudo, se observou, para os usos F e P, que na camada subsuperficial se apresentaram similares ao uso $\mathrm{V}$ para a mesma camada (Figura 2); o mesmo não se verificou para os usos C e D em relação a V; considerando-se a camada subsuperficial (Figura 2), concluiu-se que, nesses usos, as alterações de manejo atingiram esta camada de maneira expressiva.

Os usos C e D tiveram características similares na camada de $0-10 \mathrm{~cm}$ formando um grupo; houve variação da qualidade do solo para esses usos que, juntos, constituíram outro grupo na camada de 10-30 cm (Figura 2); o mesmo se deu para $\mathrm{F}$ e $\mathrm{P}$, reunidos em um grupo em função dos atributos analisados na camada de $0-10 \mathrm{~cm}$ e em outro, pelos atributos da camada de 10-30 cm (Figura 2). No mesmo grupo, que reuniu F e $\mathrm{P}$ pelos atributos analisados na camada de $10-30 \mathrm{~cm}$, encontrou-se V, que participou para os atributos analisados na camada de 0-10 e 10-30 cm, demonstrando que nesses usos 
as alterações físicas foram menores que as sofridas em C e D apresentando, portanto, melhor qualidade do solo (Figura 2).

\section{CONCLUSÕES}

1. O uso agrícola promoveu alterações nos atributos físi$\cos$ dos solos em relação ao solo sob vegetação nativa.

2. A qualidade do solo para os atributos físicos variou entre as camadas de 0-10 e 10-30 cm, exceto para o uso V (vegetação nativa), que teve qualidade similar nessas camadas.

3. Os usos F (fruticultura) e P (pastagem) tiveram melhor qualidade física do solo em relação ao uso C (ciclo curto), nas camadas de 0-10 e $10-30 \mathrm{~cm}$.

4. O uso D (descartada) teve a pior qualidade do solo nas camadas avaliadas.

\section{LITERATURA CITADA}

Anjos, J. T.; Uberti, A. A. A.; Vizzotto, V. J.; Leite, G. B.; Kreiger, M. Propriedades físicas em solos sob diferentes sistemas de uso e manejo. Revista Brasileira de Ciência do Solo, v.18, p.139-145, 1994.

Araújo, M. A.; Tormena, C. A.; Silva, A. P. Propriedades físicas de um latossolo vermelho distrófico cultivado e sob mata nativa. Revista Brasileira de Ciência do Solo, v.28, p.337345, 2004.

Barber, R. G.; Orellnan, M.; Navarro, F.; Diaz, O; Soruco, M. A. Effects of conservation and conventional tillage systems after land clearing on soil properties and crop yield in Santa Cruz, Bolivia. Soil and Tillage Research, v.38, p.133-152, 1996.

Barreto, A. C.; Lima, F. H. S.; Freire, M. B. G. S.; Araújo, Q. R.; Freire, F. J. Características químicas e físicas de um solo sob floresta, sistema agroflorestal e pastagem no Sul da Bahia. Caatinga, v.19, n.4, p.415-425, 2006.

Borges, T. A.; Oliveira, F. A.; Silva, E. M. da; Goedert, W. J. Avaliação de parâmetros fisico-hídricos de Latossolo Vermelho sob pastejo e sob cerrado. Revista Brasileira de Engenharia Agrícola e Ambiental, v.13, n.1, p.18-25, 2009.

Carpenedo, V.; Mielniczuk, J. Estado de agregação e qualidade de agregados de Latossolos Roxos, submetidos a diferentes sistemas de manejo. Revista Brasileira de Ciência do Solo, v.14, p.99-105, 1990.

Corrêa, R. M.; Freire, M. B. G.; Ferreira, R. L. C.; Freire, F. J. F.; Pessoa, L. G. M.; Miranda, M. A.; Melo, D. V. M. Atributos químicos de solos sob diferentes usos em perímetro irrigado no semiárido de Pernambuco. Revista Brasileira de Ciência do Solo, v.33, p.305-314, 2009.

Cruz, C. D.; Regazzi, A. J.; Carneiro, P. C. S. Modelos biométricos aplicados ao melhoramento genético. 3.ed. Viçosa: UFV, 2004. 480p.

Cunha, T. J. F.; Macedo, J. R.; Ribeiro, L. P.; Freitas, F. P. P. L.; Aguiar, A. C. Impacto do manejo convencional sobre propriedades físicas e substâncias húmicas de solos sob cerrado. Ciência Rural, v.1, n.1, p.27-36, 2001.
EMBRAPA - Empresa Brasileira de Pesquisa Agropecuária. Manual de métodos de análises de solo. 2.ed. Rio de Janeiro: CNPS, 1997. 212p.

Fidalski, J.; Tormena, C. A.; Scapim, C. A. Espacialização vertical e horizontal dos indicadores de qualidade para um Latossolo Vermelho cultivado com citros. Revista Brasileira de Ciência do Solo, v.31, n.2, p.9-19, 2007.

Figueiredo, C. C. de; Santos, G. G.; Pereira, S.; Nascimento, J. L. do; Alves Júnior, J. Propriedades físico-hídricas em Latossolo do Cerrado sob diferentes sistemas de manejo. Revista Brasileira de Engenharia Agrícola e Ambiental, v.13, n.2, p.146151, 2009.

Leonardo, H. C. L. Indicadores de qualidade de solo e água para a avaliação do uso sustentável da microbacia hidrográfica do rio Passo Cue, região oeste do estado do Paraná. Piracicaba: USP, 2003. 131p. Dissertação Mestrado

Maia, S. M. F.; Xavier, F. A. S.; Oliveira, T. S.; Mendonça, E. S.; Araújo Filho, J. A. Impactos de sistemas agroflorestais e convencional sobre a qualidade do solo no semi-árido cearense. Revista Árvore, v.30, n.5, p.837-848, 2006.

Meunier, I. M. J.; Silva, J. A. A.; Ferreira, R. L. C. Inventário florestal: programas de estudo. 1.ed. Recife: Impressa Universitária da UFRPE, 2001. 189p.

Prado, R. M.; Centurion, J. F. Alterações na cor e no grau de floculação de um Latossolo Vermelho-Escuro sob cultivo contínuo de cana-de-açúcar. Pesquisa Agropecuária Brasileira, v.36, p.197-203, 2001.

Rao, C. R. Advanced statistical methods in biometric research, 1.ed. New Delhi: John Wiley \& Sons, 1952. 390p.

Rosa Júnior, E. J.; Martins, R. M. G.; Rosa, Y. B. C. J.; Cremon, C. Calcário e gesso como condicionantes físico e químico de um solo de cerrado sob três sistemas de manejo, Pesquisa Agropecuária Tropical, v.36, n.1, p.37-44, 2006.

Silva, A. J. N.; Cabeda, M. S. V.; Carvalho, F. G.; Lima, J. F. W. F. Alterações físicas e químicas de um Argissolo amarelo sob diferentes sistemas de uso e manejo. Revista Brasileira de Engenharia Agrícola e Ambiental, v.10, n.1, p.76-83, 2006.

Silva, I. F.; Mielniczuk, J. Ação do sistema radicular de plantas na formação e estabilização de agregados do solo. Revista Brasileira de Ciência do Solo, v.21, p.113-117, 1997.

Silva, M. A. S.; Mafra, A. L.; Albuquerque, J. A.; Bayer, C.; Mielniczuk, J. Atributos físicos do solo relacionados ao armazenamento de água em um Argissolo Vermelho sob diferentes sistemas de preparo. Ciência. Rural, v.35, n.3, p.544-552, 2005.

Souza, E. D.; Carneiro, M. A. C.; Paulino, H. B. Atributos físicos de um Neossolo Quartzarênico e um Latossolo Vermelho sob diferentes sistemas de manejo. Pesquisa Agropecuária Brasileira, v.40, n.11, p.1135-1139, 2005.

Souza, G. S. Introdução aos modelos de regressão linear e não-linear. 2.ed. Brasília: Embrapa-SPI, 2001. 489p.

Su, Y. Z.; Zhao, H. L.; Zhang, T. H.; Zhao, X. Y. Soil properties following cultivation and non-grazing of a semi-arid sandy grassland in northern China. Soil \& Tillage Research, v.75, n.1 p.27-36, 2004.

THEMAG - Engenharia e Gerenciamento Ltda. Relatório de estudos edafoclimáticos dos projetos Chesf da Borda do Lago de Itaparica - margem esquerda, Recife: THEMAG, 1986. 214p. 